\title{
Influential Parameters of Starching Process on Mechanical Properties of Yarns Intended for Multifunctional Woven Fabrics for Thermal Protective Clothing
}

\author{
Ivana Schwarz ${ }^{1, *} \mathbb{0}$, Stana Kovačević ${ }^{1}\left(\mathbb{D}\right.$ and Ivana Vitlov ${ }^{2}$ \\ 1 Department of Textile Design and Management, Faculty of Textile Technology, University of Zagreb, \\ Prilaz baruna Filipovića 28a, 10000 Zagreb, Croatia; stana.kovacevic@ttf.unizg.hr \\ 2 School of Applied Arts and Design, Perivoj Vladimira Nazora 3/3, 23000 Zadar, Croatia; \\ ivana.vitlov@skole.hr \\ * Correspondence: ivana.schwarz@ttf.unizg.hr
}

Citation: Schwarz, I.; Kovačević, S.; Vitlov, I. Influential Parameters of Starching Process on Mechanical Properties of Yarns Intended for Multifunctional Woven Fabrics for Thermal Protective Clothing. Polymers 2021, 13, 73.

https://dx.doi.org/10.3390/polym 13010073

Received: 10 December 2020 Accepted: 23 December 2020 Published: 27 December 2020

Publisher's Note: MDPI stays neutral with regard to jurisdictional claims in published maps and institutional affiliations.

Copyright: (c) 2020 by the authors. Licensee MDPI, Basel, Switzerland. This article is an open access article distributed under the terms and conditions of the Creative Commons Attribution (CC BY) license (https: / / creativecommons.org/ licenses/by/4.0/).

\begin{abstract}
The investigation of influential parameters of the starching process on mechanical properties of yarns intended for multifunctional woven fabrics for thermal protective clothing was performed on four different yarn samples starched on an innovative starching machine, adapted to industrial starching conditions. The starching was conducted with two different processes with different starch mass concentrations: the standard starching process and a newer starching process (with yarn prewetting). Based on the results obtained, it can be concluded that starching positively affects all the properties of tested samples and that the increase of starch mass concentration is not accompanied by the improvement of those yarn properties. Synthetic polymer fibers that achieve satisfactory yarn strength need to be starched with lower starch mass concentrations in order to retain the breaking properties and to be protected from abrasion and static electricity, which occurs during the weaving process. The yarn prewetting starching process shows significantly better results than the standard starching process, especially for aramid yarns, where abrasion resistance increased from 42 to $135 \%$. Therefore, we can conclude that the goal of starching such yarns is aimed at increasing the wear resistance. Linear regressions and correlations between the values of breaking properties and abrasion resistance obtained by the testing and their values that were estimated by the analysis show a high correlation coefficient.
\end{abstract}

Keywords: starching; yarns for thermal protective clothing; mechanical properties; laboratory starching machine

\section{Introduction}

In today's wide field of protective textiles, great emphasis is on the production of woven fabrics, where design, construction solutions and use of new and diverse textile fibers can influence the achievement of a wide range of requirements, in order to obtain multifunctional multilayer woven fabrics [1,2].

Beside the ability to provide a high level of protection, protective clothing must have the properties of comfort and durability. The fabrics used for this purpose are mostly singlelayer flat products, which represent the top layer (in composite materials) of protective clothing. Composite materials used for protective purposes are composed of several diverse materials. The upper layer is a woven fabric, which is joined by other layers that differ from woven fabric by their structures, raw materials and properties. It is becoming more demanding, complex and difficult to achieve certain material properties, prescribed by standards for a particular purpose, and it is even more difficult to achieve the sustainability during use. Therefore, finishing processes (surface treatments and layering) are conducted on the material, which simultaneously affect the property of breathability, resulting in the insufficient material comfort [3-7]. 
Woven fabrics are complex structures whose ultimate properties are conditioned by parameters at the macro-level, meso-level and micro-level. The macrolevel implies the woven fabric construction parameters, the meso-level implies the yarn structural parameters of which the fabric is composed, while the microlevel implies the properties of the fibers. Thus, fibers, with all their properties, carry the fundamental properties of any woven fabric [8].

Fibers used today for production of woven fabrics for protective clothing, which have a high degree of thermal protection, are aramid fibers, especially meta-aramid fibers. They are characterized by exceptional properties such as fire resistance, thermal stability, thermal conductivity, thermal resistance (does not lose strength properties under permanent load at elevated temperatures up to $180^{\circ} \mathrm{C}$ ), exceptional mechanical properties (high strength properties), good heat insulation, resistance to peeling, antistatic properties and are easy to maintain [9]. Very significant are modacrylic fibers (MAC), which are characterized by high flame retardancy, satisfactory abrasion resistance, softness and pliability, suitability for dyeing and durability. Blends of these fibers with polymer FR (flame retardancy) fibers are most often used for thermal protection, but their independent use is also important. In order to achieve the comfort, other fibers are also used in blends with these fibers, such as cotton and polyamide (PA) fibers, as the inner layer of protective clothing [10-13]. An increasing share of synthetic fibers in woven fabric production processes (especially technical fabrics for protective clothing), have relatively small surface masses, extremely fine threads and relatively high densities, so they require intensive and continuous monitoring during fabric production stages, in order to meet set standards. Some of the filament or spun synthetic yarns have satisfactory physical-mechanical properties, such as strength, abrasion resistance, elasticity, as well as resistance to long-term cyclic stresses, so they do not need to be starched. Since the starching process is the most expensive process in woven fabric production, it should be avoided whenever possible. However, sometimes its implementation is necessary in order to improve the yarn physical-mechanical parameters relevant to the further weaving process, in terms of: reducing the number of warp thread breaks to a minimum, achieving the maximum degree of weaving machine utilization and increasing the quality of the finished fabric. There are no standardized methods that will give the exact information on which yarn should or should not be starched. Therefore, a comprehensive analysis of yarn, target woven fabric, weaving machine and production process conditions is needed to get the best answer to the question: whether a particular yarn needs to be starched, to what extent or whether the starching is even necessary [14-29].

In this paper, the purpose of starching yarns intended for the production of multifunctional woven fabrics for thermal protective clothing will be investigated. The question arises, whether these yarns need to be starched, and if so, by which starching process and under what starching conditions. The implementation of the research and the comparative analysis of the results obtained will provide insight into the yarn mechanical properties, considering very important ecological and economic segment.

\section{Materials and Methods}

Due to easier and more economical regulation of starching conditions, a laboratory starching machine for samples preparation was used. Two starching processes were applied: the standard starching process and the newer prewetting starching process. The possibility of implementing both starching processes on a laboratory starching machine, constructed at the University of Zagreb, Faculty of Textile Technology, Zagreb, Croatia (recognized as consensual patents no. PK20070247 and PK20070248, State Intellectual Property Office of the Republic of Croatia) is significant. Laboratory starching conditions are adapted to industrial ones, and the method of starching is shown in Figure 1. 


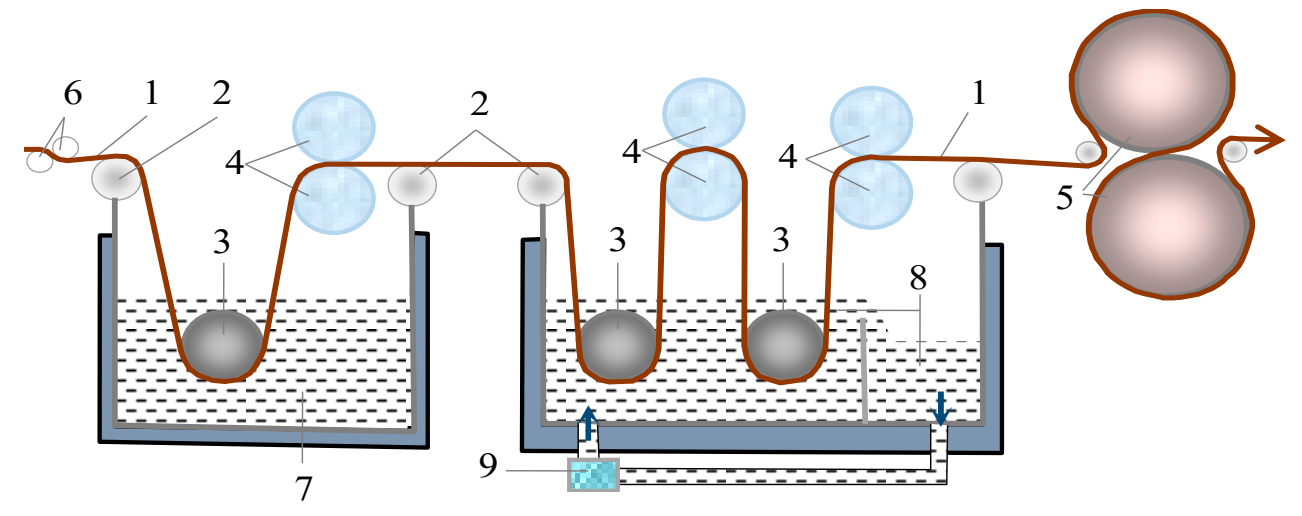

Prewetting box

Starching box

Figure 1. Scheme of a laboratory starching machine, where: 1-yarn, 2-rollers for guiding threads, 3-rollers for immersion in water and starch mass, 4-rollers for squeezing out excess water and starch mass, 5-rollers for contact drying, 6-tensiometer, 7-hot prewetting water, 8-starch mass, 9-starch mass circulation pump.

The tests necessary to draw relevant conclusions were performed on four different yarn samples whose basic properties are shown in Table 1.

Table 1. Tested yarn properties.

\begin{tabular}{|c|c|c|c|c|c|c|c|c|}
\hline \multirow{2}{*}{$\begin{array}{l}\text { Parameters } \\
\text { Raw material }\end{array}$} & \multicolumn{2}{|c|}{ Sample I } & \multicolumn{2}{|c|}{ Sample II } & \multicolumn{2}{|c|}{ Sample III } & \multicolumn{2}{|c|}{ Sample IV } \\
\hline & PA & cotton & PA & cotton & cotton & MAC & $\mathrm{p}-\mathrm{AR}$ & $\mathrm{m}-\mathrm{AR}$ \\
\hline Ratio (\%) & $50 \%$ & $50 \%$ & $50 \%$ & $50 \%$ & $45 \%$ & $55 \%$ & $5 \%$ & $95 \%$ \\
\hline Finesses $(\mathrm{Nm})$ & \multicolumn{2}{|c|}{$\mathrm{Nm} 70 / 2$} & \multicolumn{2}{|c|}{$\mathrm{Nm} 65 / 2$} & \multicolumn{2}{|c|}{$\mathrm{Nm} 40 / 1$} & \multicolumn{2}{|c|}{$\mathrm{Nm} 60 / 2$} \\
\hline Real finesses (Nm) & \multicolumn{2}{|c|}{$69.36 / 2$} & \multicolumn{2}{|c|}{$65.55 / 2$} & \multicolumn{2}{|c|}{$39.69 / 1$} & \multicolumn{2}{|c|}{$59.28 / 2$} \\
\hline Twists (twist/m) & \multicolumn{2}{|c|}{787.10} & \multicolumn{2}{|c|}{748.16} & \multicolumn{2}{|c|}{891.70} & \multicolumn{2}{|c|}{323.20} \\
\hline
\end{tabular}

These fibers are used specifically in conditions of thermal protection, where it is extremely important to know and consider their advantages and disadvantages (Table 2).

Table 2. Yarn performance characteristics.

\begin{tabular}{|c|c|}
\hline m-AR (meta-aramid) & $\begin{array}{l}\text { High inherent flammability (high LOI, marginal oxygen index, 27-42) } \\
\text { High strength } \\
\text { Good dimensional stability } \\
\text { Inferior textile-process properties }\end{array}$ \\
\hline p-AR (para-aramid) & $\begin{array}{l}\text { High inherent flammability (high LOI, limit oxygen index, 29) } \\
\text { High strength, dimensional stability and resistance to chemicals } \\
\text { Inferior textile-process properties } \\
\text { Low degree of stability to solar radiation }\end{array}$ \\
\hline MAC (modacrylic) & $\begin{array}{l}\text { High inherent flammability (high LOI, marginal oxygen index, 30) } \\
\text { High degree of compatibility in the mixture } \\
\text { Good fire resistance }\end{array}$ \\
\hline PA (polyamide) & $\begin{array}{l}\text { Low inherent flammability (low LOI, limiting oxygen index, 20) } \\
\text { High strength } \\
\text { Antistatic properties } \\
\text { Good dimensional stability }\end{array}$ \\
\hline Cotton & $\begin{array}{l}\text { Flammable (low LOI, oxygen limit, 16-18) } \\
\text { High comfort properties } \\
\text { Increased wet strength } \\
\text { Poor dimensional stability }\end{array}$ \\
\hline
\end{tabular}


Starch agents and their share in the starch mass, which are commonly used in the industry for the types of yarns listed above, were selected for this research, because they are most suitable for the selected yarns (due to yarn types and fibers), as well as for the requirements of the starching process and further weaving process.

Starch agents used for starching processes were Fibrosint C75 (Pulcra Chemicals $\mathrm{GmbH}$; synthetic polymer, Geretsried, Germany) and Inex 773C (Pulcra Chemicals GmbH; chemical composition: polyvinyl alcohol, Geretsried, Germany) in concentrations of $5 \%$, $7 \%$ and $10 \%$, and according to the proportions shown in the Table 3.

Table 3. Starch agents and their proportions in starch mass.

\begin{tabular}{lcccc}
\hline \multirow{2}{*}{ Starch Mass Composition } & \multicolumn{2}{c}{ Industrial Values } & \multicolumn{2}{c}{ Laboratory Values } \\
\cline { 2 - 5 } & L or kg & vol (\%) & L or kg & vol (\%) \\
\hline Water (L) & 500 & 88.03 & 5.00 & 88.03 \\
Fibrostin C75 (kg) & 50 & 8.80 & 0.50 & 8.80 \\
Inex 773C (kg) & 15 & 2.64 & 0.15 & 2.64 \\
Avilor 308AS (kg) & 3 & 0.53 & 0.03 & 0.53 \\
Starching mass (L) & 568 & 100 & 5.68 & 100 \\
\hline
\end{tabular}

During the starching process, all conditions affecting the starch pickup were achieved and kept constant (Table 4). The process was carried out by simultaneous starching of five threads at a length of $200 \mathrm{~m}$.

Table 4. Conditions during the starching process.

\begin{tabular}{lr}
\hline Condition & Value \\
\hline Thread tension before prewetting box & $40 \mathrm{cN}$ \\
Water temperature in the prewetting box & $65^{\circ} \mathrm{C}$ \\
Starch temperature in the starch box & $75^{\circ} \mathrm{C}$ \\
Starching speed & $3 \mathrm{~m} / \mathrm{min}$ \\
Pressure on the last pair of rollers for squeezing excess starch mass & $19.1 \mathrm{~N} / \mathrm{cm}^{2}$ \\
Temperature on the contact dryer cylinders & $140^{\circ} \mathrm{C}$ \\
\hline
\end{tabular}

Determination of yarn mechanical properties was performed according to the following methods:

- Yarn breaking properties, which include the following properties: breaking force $\mathrm{F}(\mathrm{cN})$, elongation at break $\varepsilon(\%)$ and tenacity $\sigma(\mathrm{cN} /$ tex -according to ISO 2062, on the Statimat M tensile tester, t.t. Textechno, Mönchengladbach, Germany;

- Yarn abrasion resistance, A (no. cycles) - the abrasion resistance test was performed on a Zweigle Abrasion Tester G551, Zweigle, Reutlingen, Germany, where each of the 20 threads, under a load of $20 \mathrm{~g}$, is simultaneously subjected to the abrasion process until the thread breaks. The movement of the roller coated with sandpaper (finesses 600), left-right and rotating around its axis, achieves a certain intensity of yarn and sandpaper abrasion. During abrasion, the thread weakens and at the moment when the mass of the weight suspended on the thread exceeds the yarn strength, an interruption occurs and the number of movements is registered.

\section{Results}

The reliability of the results obtained by the conducted tests was confirmed and supported by statistical processing and analysis, where the indicators of result variability and reliability are shown in Table 5 .

The results of conducted tests of yarn breaking properties and abrasion resistance (before and after starching, with and without prewetting and with three starch mass concentrations) are shown graphically in Figures 2-5. They are crucial for defining the 
success of the starching process, and thus continuing the weaving process and for proving the justification of the process described.

The results obtained and their multiple regression analysis show that there is a strong influence of a large number of existing independent variables (predictors) on the dependent variance (criterion) and it is possible to achieve a high correlation. The aim of the regression analysis is to determine the extent to which the linear combination of predictors interprets the variations of the criteria and the extent of the contribution, i.e., the importance of individual predictors. Predictors that are of great importance for achieving maximum correlation with the criterion depend on the criterion itself (YS represent the criterion for the standard starching process, YP represent the criterion for the prewetting starching process). In this case they were yarn real fineness before starching (X1), yarn twists before starching (X2) and starch mass concentration (X3). Graphical representations of multiple regression analysis of the results obtained, with the corresponding equations of multiple regression and highly achieved correlations between the values obtained by testing and the statistically estimated criteria, are shown in Figures 2-5.

Table 5. Statistical indicators of the tested yarn values.

\begin{tabular}{|c|c|c|c|c|c|c|c|}
\hline & & \multicolumn{3}{|c|}{ Sample 1} & \multicolumn{3}{|c|}{ Sample 2} \\
\hline & & $\bar{X}$ & CV (\%) & $\mathrm{p}_{\mathrm{gg}}(\%)$ & $\bar{X}$ & CV (\%) & $\mathrm{p}_{\mathrm{gg}}(\%)$ \\
\hline \multirow{7}{*}{$\mathrm{F}(\mathrm{cN})$} & Unstarched & 507.62 & 10.53 & 2.84 & 589.92 & 7.73 & 2.07 \\
\hline & S 5\% & 536.64 & 10.49 & 2.65 & 622.17 & 7.37 & 1.86 \\
\hline & P 5\% & 550.76 & 9.32 & 2.36 & 639.75 & 7.73 & 1.96 \\
\hline & S 7\% & 520.05 & 7.99 & 2.14 & 602.68 & 7.23 & 2.20 \\
\hline & Р 7\% & 531.84 & 9.37 & 2.37 & 611.43 & 7.86 & 2.54 \\
\hline & S 10\% & 536.54 & 7.53 & 1.90 & 630.60 & 6.82 & 1.72 \\
\hline & P $10 \%$ & 545.13 & 9.43 & 2.30 & 642.05 & 7.99 & 2.02 \\
\hline \multirow{7}{*}{$\varepsilon(\%)$} & Unstarched & 14.15 & 21.09 & 5.35 & 14.41 & 12.66 & 3.20 \\
\hline & S 5\% & 10.50 & 29.87 & 7.57 & 12.14 & 13.81 & 3.50 \\
\hline & P 5\% & 9.80 & 31.69 & 8.00 & 10.43 & 25.10 & 6.36 \\
\hline & S 7\% & 9.70 & 29.20 & 7.38 & 11.01 & 21.00 & 5.42 \\
\hline & P 7\% & 8.11 & 33.90 & 7.52 & 8.70 & 32.41 & 8.20 \\
\hline & S $10 \%$ & 8.48 & 36.15 & 9.16 & 10.65 & 18.73 & 4.73 \\
\hline & P $10 \%$ & 7.35 & 39.49 & 9.98 & 10.21 & 23.17 & 6.44 \\
\hline \multirow{7}{*}{$\sigma(\mathrm{cN} /$ tex $)$} & Unstarched & 17.75 & 10.53 & 2.84 & 19.66 & 7.73 & 2.07 \\
\hline & S 5\% & 18.76 & 10.49 & 2.66 & 20.74 & 7.37 & 1.87 \\
\hline & P 5\% & 19.26 & 9.32 & 2.35 & 21.33 & 7.73 & 1.96 \\
\hline & S 7\% & 18.18 & 7.99 & 2.14 & 20.09 & 7.23 & 2.20 \\
\hline & P 7\% & 18.60 & 9.37 & 2.37 & 20.38 & 7.86 & 2.53 \\
\hline & S 10\% & 18.76 & 7.53 & 1.90 & 21.02 & 6.82 & 1.72 \\
\hline & P $10 \%$ & 19.06 & 9.43 & 2.30 & 21.40 & 7.99 & 2.02 \\
\hline \multirow{7}{*}{ A (No. cycle) } & Unstarched & 2021.75 & 21.05 & 5.33 & 2108.30 & 30.74 & 7.78 \\
\hline & S 5\% & 2059.90 & 18.19 & 4.60 & 2674.40 & 21.93 & 5.55 \\
\hline & P 5\% & 2603.00 & 21.20 & 5.36 & 2748.70 & 15.50 & 3.92 \\
\hline & $\mathrm{S} 7 \%$ & 2350.85 & 27.29 & 6.91 & 2683.10 & 25.72 & 6.51 \\
\hline & P 7\% & 2733.30 & 15.24 & 3.86 & 2960.00 & 16.33 & 4.13 \\
\hline & S 10\% & 2455.00 & 20.15 & 5.10 & 3258.40 & 28.79 & 7.29 \\
\hline & P $10 \%$ & 3086.90 & 17.64 & 4.46 & 3641.20 & 16.42 & 4.16 \\
\hline
\end{tabular}


Table 5. Cont.

\begin{tabular}{|c|c|c|c|c|c|c|c|}
\hline & & \multicolumn{3}{|c|}{ Sample 3} & \multicolumn{3}{|c|}{ Sample 4} \\
\hline & & $\bar{X}$ & CV (\%) & $p_{g g}(\%)$ & $\bar{X}$ & CV (\%) & $p_{g g}(\%)$ \\
\hline \multirow{7}{*}{$\mathrm{F}(\mathrm{cN})$} & Unstarched & 218.77 & 8.06 & 2.04 & 635.44 & 7.30 & 1.85 \\
\hline & $\mathrm{S} 5 \%$ & 285.99 & 8.57 & 2.17 & 681.38 & 7.16 & 1.81 \\
\hline & P $5 \%$ & 292.77 & 7.02 & 1.78 & 690.88 & 5.05 & 1.28 \\
\hline & S 7\% & 285.34 & 5.57 & 1.44 & 661.83 & 7.61 & 1.93 \\
\hline & P 7\% & 292.52 & 6.94 & 1.71 & 664.21 & 8.06 & 2.03 \\
\hline & S $10 \%$ & 293.52 & 8.44 & 1.29 & 671.12 & 8.29 & 2.10 \\
\hline & P $10 \%$ & 296.35 & 7.04 & 1.76 & 704.73 & 7.99 & 2.02 \\
\hline \multirow{7}{*}{$\varepsilon(\%)$} & Unstarched & 4.67 & 13.25 & 3.36 & 20.34 & 9.97 & 2.53 \\
\hline & S $5 \%$ & 4.55 & 23.44 & 5.95 & 19.24 & 14.68 & 3.71 \\
\hline & Р 5\% & 3.35 & 9.22 & 2.34 & 20.07 & 10.50 & 2.66 \\
\hline & S 7\% & 4.27 & 8.55 & 2.19 & 18.87 & 13.91 & 3.53 \\
\hline & P 7\% & 2.98 & 9.25 & 2.38 & 19.33 & 10.38 & 2.63 \\
\hline & S $10 \%$ & 3.79 & 13.58 & 3.40 & 18.74 & 14.70 & 3.71 \\
\hline & P 10\% & 3.25 & 10.28 & 2.57 & 19.26 & 13.09 & 3.31 \\
\hline \multirow{7}{*}{$\sigma(\mathrm{cN} /$ tex $)$} & Unstarched & 8.75 & 8.06 & 2.05 & 19.26 & 7.30 & 1.84 \\
\hline & S $5 \%$ & 11.44 & 8.57 & 2.17 & 20.65 & 7.16 & 1.81 \\
\hline & P 5\% & 11.71 & 7.02 & 1.77 & 20.94 & 5.05 & 1.28 \\
\hline & S 7\% & 11.41 & 5.57 & 1.44 & 20.06 & 7.61 & 1.93 \\
\hline & P $7 \%$ & 11.70 & 6.94 & 1.71 & 20.13 & 8.06 & 2.04 \\
\hline & S $10 \%$ & 11.75 & 8.44 & 2.15 & 20.34 & 8.29 & 2.09 \\
\hline & P 10\% & 11.85 & 7.04 & 1.77 & 20.39 & 7.99 & 2.12 \\
\hline \multirow{7}{*}{ A (No. cycle) } & Unstarched & 129.10 & 20.28 & 5.13 & 1450.85 & 24.81 & 6.28 \\
\hline & S $5 \%$ & 138.85 & 15.26 & 3.86 & 1673.50 & 20.27 & 5.13 \\
\hline & Р 5\% & 143.15 & 24.29 & 6.15 & 2065.20 & 24.97 & 6.32 \\
\hline & S 7\% & 153.70 & 21.02 & 5.32 & 2505.50 & 28.42 & 7.19 \\
\hline & P $7 \%$ & 184.05 & 24.83 & 6.28 & 2852.00 & 16.57 & 4.19 \\
\hline & S $10 \%$ & 247.20 & 22.04 & 5.58 & 3079.25 & 15.97 & 4.04 \\
\hline & P $10 \%$ & 258.70 & 22.63 & 5.73 & 3418.60 & 19.32 & 4.89 \\
\hline
\end{tabular}

where $\mathrm{F}(\mathrm{cN})$-breaking force, $\varepsilon(\%)$ - elongation at break, $\sigma$ (cN/tex)—tenacity, A (No. cycles)— abrasion resistance, $\bar{X}$-mean, CV (\%)-coefficient of variation, $\mathrm{p}_{\mathrm{gg}}(\%)$-practical error limit; $\mathrm{S}$ $5 \%$-standard starching process with 5\% starch mass concentration, $\mathrm{P} 5 \%$-prewetting starching process with $5 \%$ starch mass concentration, $\mathrm{S} 7 \%$-standard starching process with $7 \%$ starch mass concentration, P $7 \%$-prewetting starching process with $7 \%$ starch mass concentration, S 10\%standard starching process with $10 \%$ starch mass concentration, P 10\%-prewetting starching process with $10 \%$ starch mass concentration.

Figure 2 shows the values of the breaking forces of the tested samples. With starching, the breaking force of all samples increases, which was expected, because breaking force increase is one of the main reasons for implementing the starching process. The smallest breaking force increase is evident for all yarns starched with a mass concentration of $7 \%$ by an average of $2-4 \%$ for the standard process and $4-5 \%$ for the prewetting process, with the exception of sample 3, where this increase is significant and amounts to $30 \%$ and $34 \%$, respectively. Opposed to that, observing the results of samples 1, 2 and 4, starched with mass concentrations of $5 \%$ and $10 \%$ (without significant deviations between the two concentrations), slightly larger improvements of this property are visible (on average $6-7 \%$ for the standard process and $8-11 \%$ for the prewetting process, while the results of sample 3 remain within the same values). That leads to the conclusion that by increasing the starch mass concentration (and thus starch pickup on the yarn) does not positively affect the increase of breaking force. Based on the results presented, it is easy to conclude that the prewetting starching process gives better results for breaking force increase and the adequacy of the starch mass concentration of $5 \%$. This is extremely important from the aspect of saving starch and other resources. The multiple regression equations are presented separately for the standard starching process and for the prewetting starching 
process, as well as for the linear regression and for correlation equations between the values obtained by the testing and analysis of the estimated breaking force values.

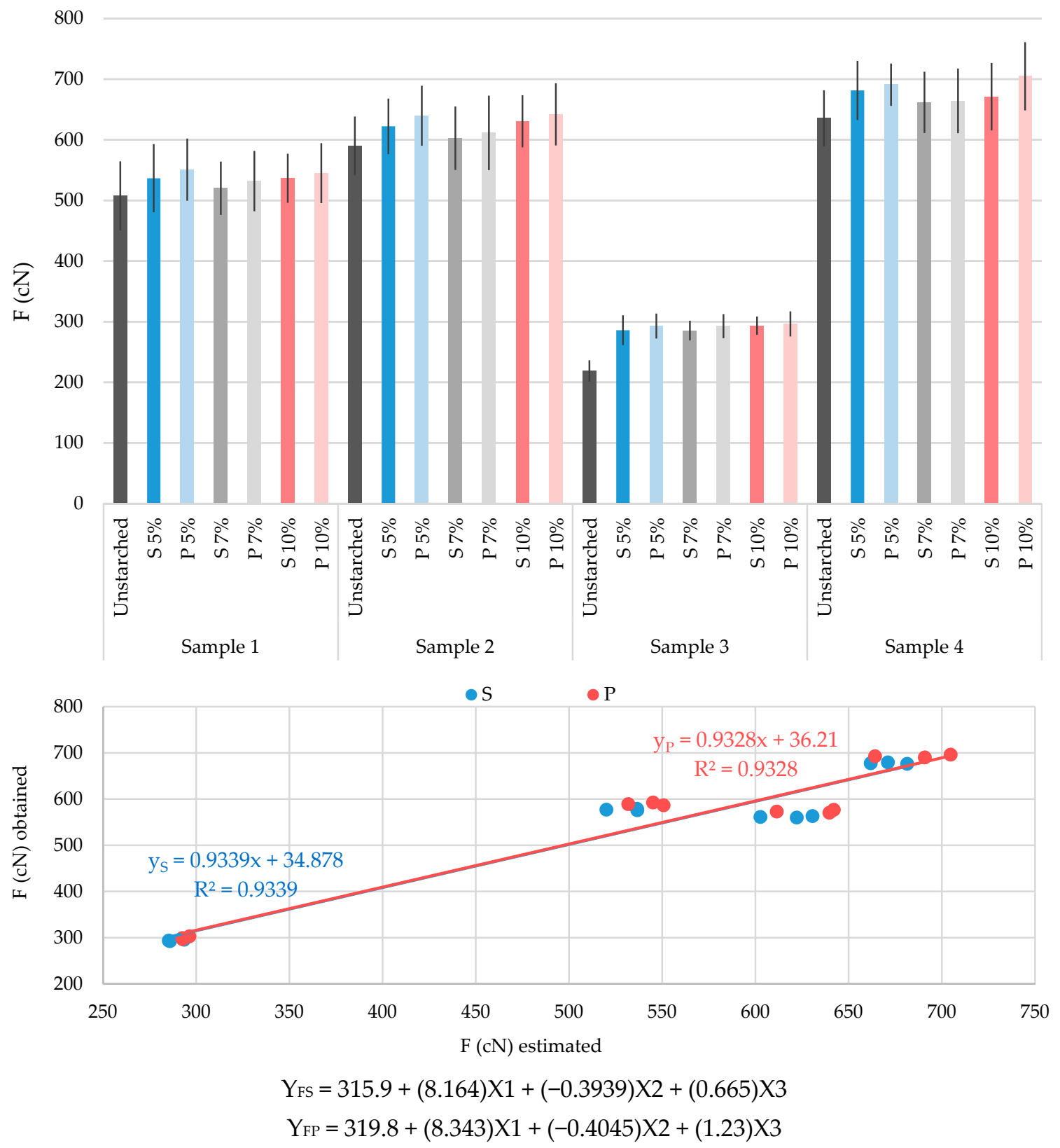

Figure 2. Diagram of breaking forces (F) of tested yarns: unstarched yarn and yarn starched by standard process (S) and by prewetting process $(\mathrm{P})$, with $5 \%, 7 \%$ and $10 \%$ starch mass concentration.

Tests of elongation at break conducted on starch yarns give very interesting results (Figure 3). In general, yarns starched with a mass concentration of $5 \%$ obtain the best results, whereas starched yarns show the smallest decrease in elasticity, which is crucial for the starching process, in order to enable successful formation of the shed with as few as possible interruptions of warp threads. The results are as follows: sample 1-decrease of $25.8 \%$ in relation to nonstarched yarns for the standard process and $30.7 \%$ in relation to nonstarched yarns for the prewetting starching process (with a difference between the two processes of only $6.7 \%$ ); sample $2-15.8 \%$ in relation to nonstarched yarns for the standard and $27.6 \%$ for the prewetting process (with a difference between the two processes of $14.1 \%$ ); sample $3-2.6 \%$ in relation to nonstarched yarns for the standard and $28.3 \%$ for the prewetting process (with a difference between the two processes of $26.4 \%$ ); sample $4-5.4 \%$ 
in relation to nonstarched yarns for the standard and $1.3 \%$ for the prewetting process (with a difference between the two processes of only $4.3 \%$ ). This means that starch from $5 \%$ concentration starch mass has the best effect on yarns applying both processes, giving the yarn high strength while retaining elasticity, but the advantage of the prewetting process is obvious.

25
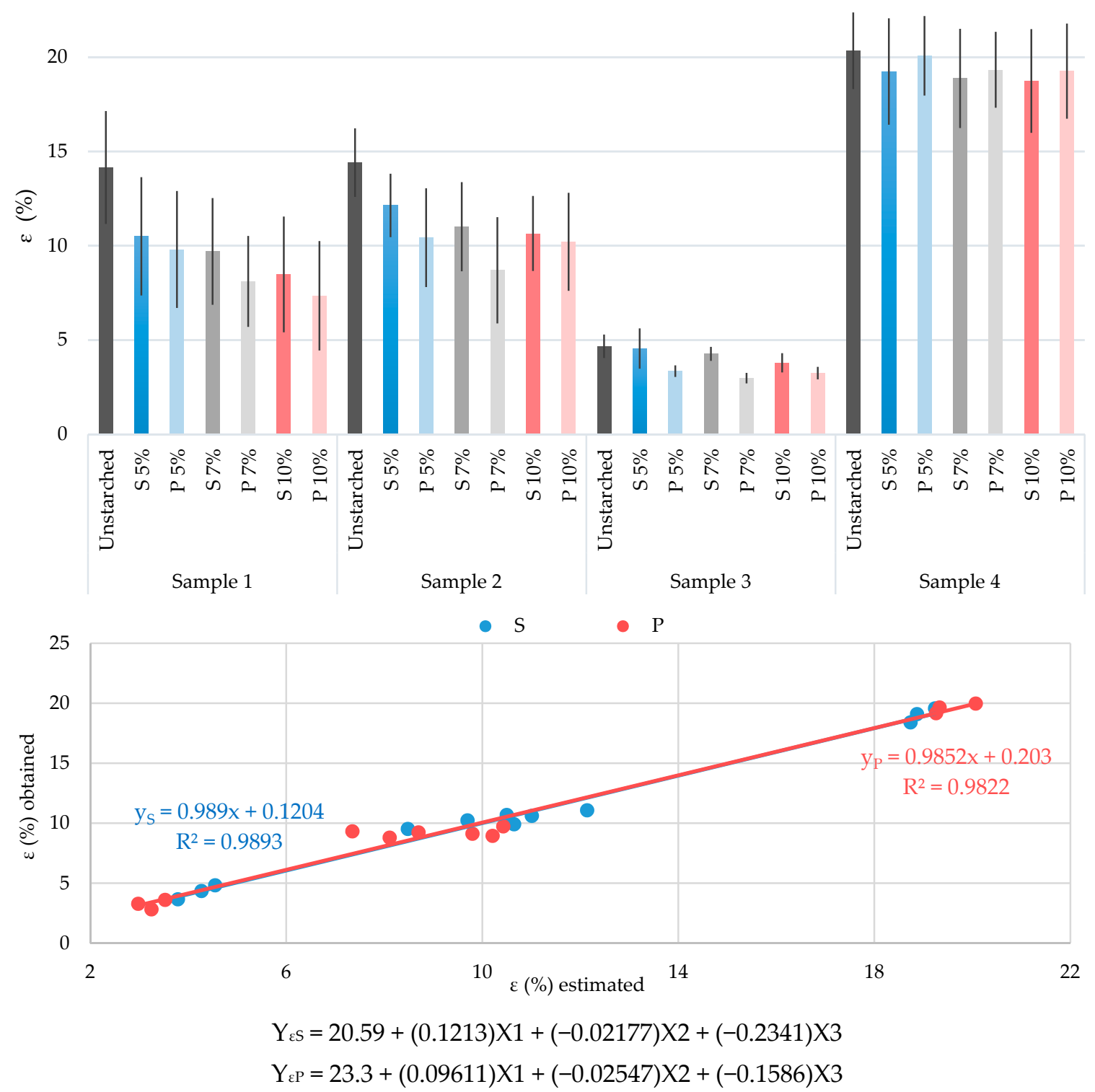

Figure 3. Diagram of elongation at break $(\varepsilon)$ of the tested yarns: unstarched yarn and starched yarn by standard and prewetting processes, with $5 \%, 7 \%$ and $10 \%$ starch mass concentration.

Increasing the concentration of starch mass reduces the properties of elongation at break. This decrease is quite pronounced for samples 1,2 and 3 (from $15 \%$ to almost $50 \%$ ), especially by applying the prewetting process. On the other hand, this decrease is almost imperceptible for sample 4 (only $1 \%$ to a maximum $8 \%$ ), where the prewetting starching process is additionally much more suitable. The difference between the two starching processes is most pronounced in sample 3, where the differences reach as much as $30 \%$ in favor of the standard starching process. 
25

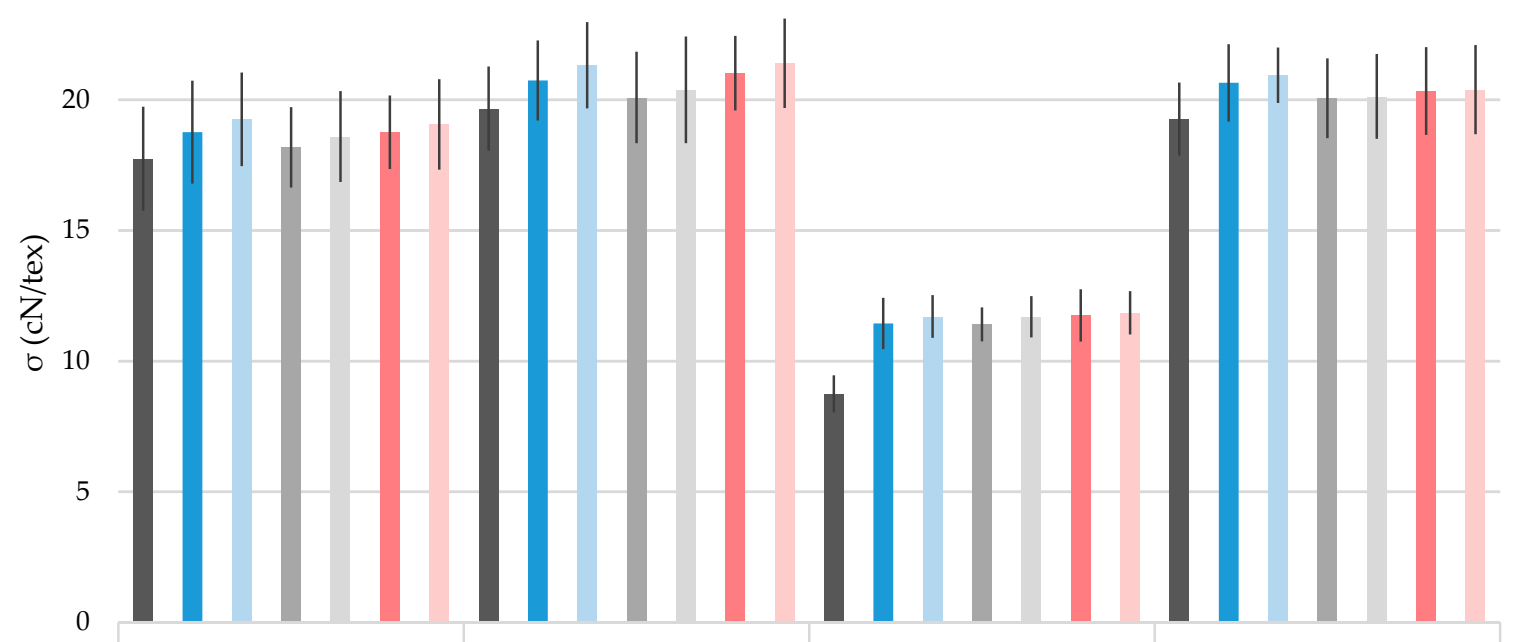

0
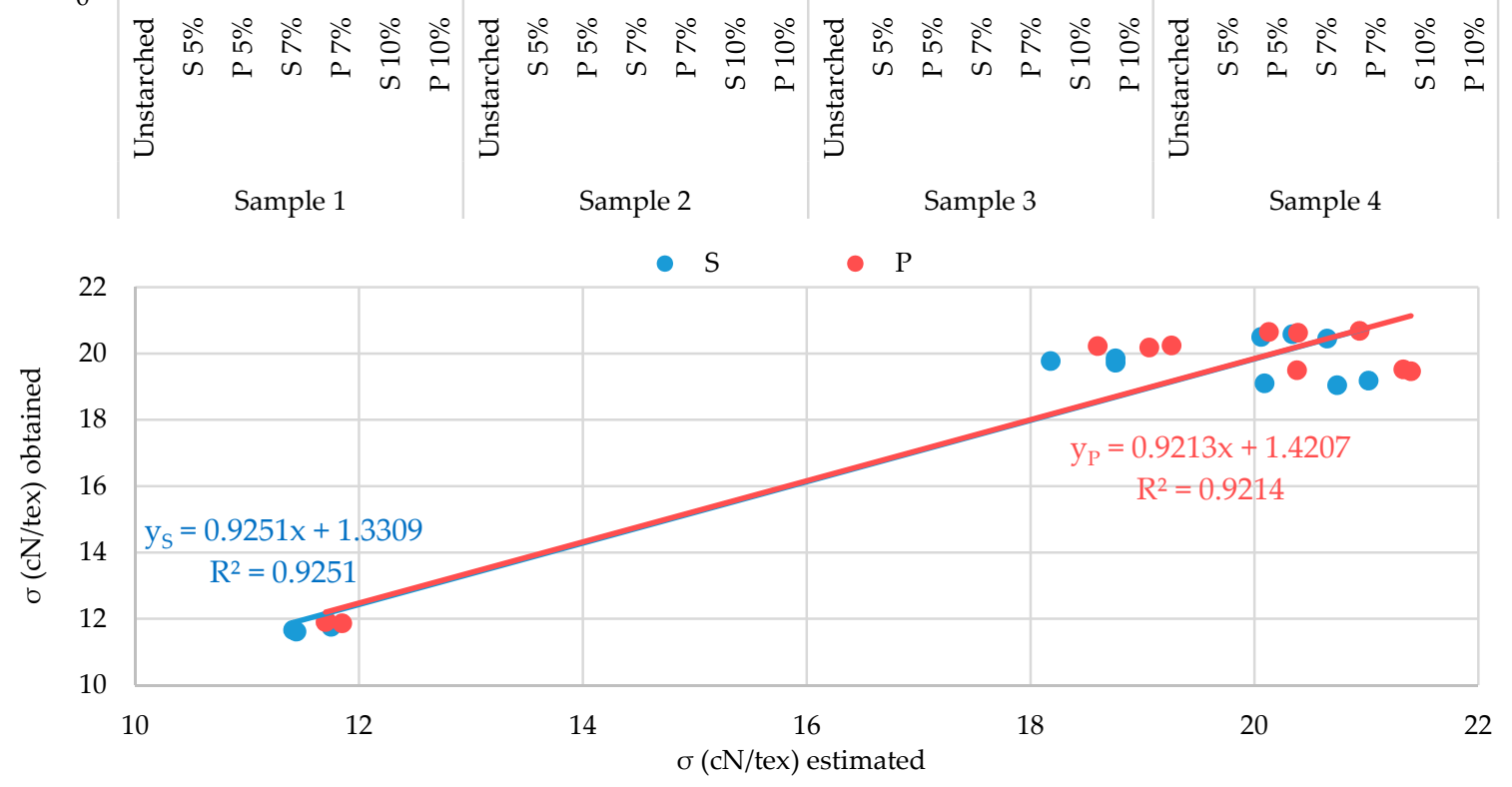

$Y_{\sigma S}=7.825+(0.2486) X 1+(-0.006972) X 2+(0.02691) X 3$
$Y_{\sigma P}=7.593+(0.2574) X 1+(-0.006526) X 2+(-0.01243) X 3$

Figure 4. Diagram of tenacity $(\sigma)$ of the tested yarns: unstarched yarns and yarns starched by standard and prewetting processes, with $5 \%, 7 \%$ and $10 \%$ starch mass concentration.

The correlation coefficients between values obtained by testing and values estimated by the multiple regression analysis, for both starching processes, are extremely high $\left(\mathrm{R}^{2}=0.98\right)$.

The results of the tested tenacity property show the expected values, since tenacity is a parameter that puts the property of breaking force and yarn fineness in the ratio (Figure 4). Greater tenacity increase is evident for yarns starched with the prewetting process with all starch mass concentrations, to a greater or lesser extent. What is important to point out once again is that the most significant results of the increase are obtained on yarns starched with the lowest mass concentration (5\%): sample 1 at $5.7 \%$, sample 2 at $5.5 \%$, sample 3 at $30.7 \%$ and sample 4 at $7.2 \%$ by applying the standard starching process; and sample 1 at $7.8 \%$, sample 2 at $8.5 \%$, sample 3 at $34.2 \%$ and sample 4 at $8.7 \%$ by applying the prewetting starching process. The weakest results of tenacity increase are on yarns starched with $7 \%$ mass concentration. Again, sample 3 shows the smallest deviations between the starched yarns, but simultaneously the largest increase in tenacity compared to unstarched yarns. 

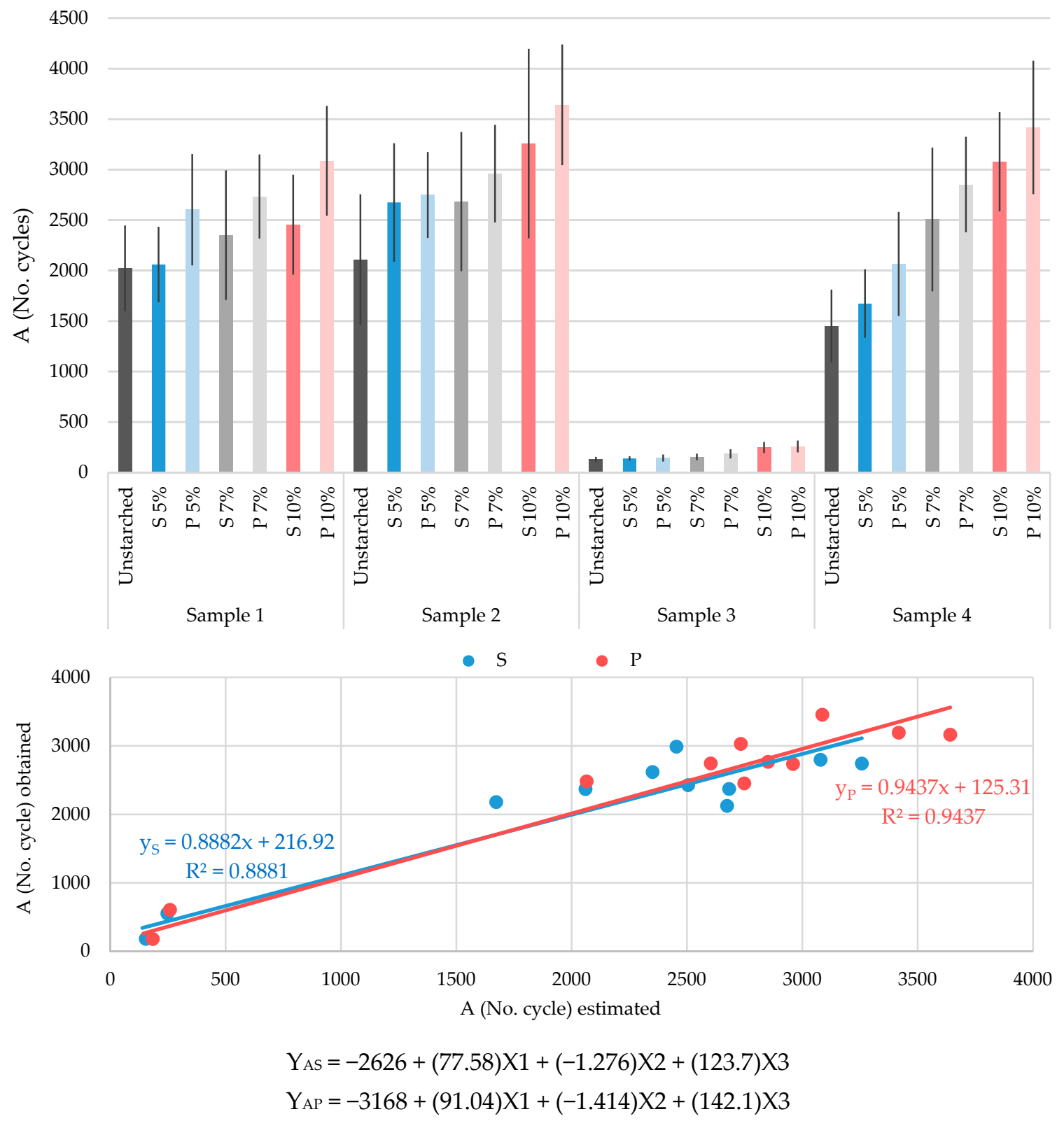

Figure 5. Diagram of abrasion resistance (A) of the tested yarns: unstarched yarns and yarns starched by standard and prewetting processes, with $5 \%, 7 \%$ and $10 \%$ starch mass concentration.

Multiple regression equations are obtained by analyzing the predictors that affect the tenacity criterion. By linear regression of values obtained by testing and estimated values of tenacity, a high degree of correlation is reached for both starching processes.

Figure 5 shows the abrasion resistance results of the tested unstarched yarns and yarns starched with all three concentrations, using both starching processes. What is most noticeable is that by increasing the starch mass concentration, the abrasion resistance for all tested samples also increases. Sample 3 stands out again, due to significantly lower values compared to other tested yarns. The abrasion resistance of unstarched yarns of samples 1 and 2 does not differ much, only $4 \%$. However, by increasing the starch mass concentration and additionally by applying the prewetting starching process, this difference significantly increases (up to over $50 \%$, or even $70 \%$ by applying the prewetting process with a $10 \%$ mass concentration). What is difficult to notice in Figure 4, but can be easily read from Table 5, is the fact that starched yarns of sample 3 achieve a marked increase in abrasion resistance, which by increasing the starch mass concentration (with a final value of $10 \%$ ), 
reach values of even $91.5 \%$ for standard starching and $100.4 \%$ for the prewetting starching process. Finally, based on the results obtained it can be concluded that sample 4 records the most significant changes, i.e., increases in abrasion resistance in relation to unstarched yarn, applying all mass concentrations, as well as starching processes. Consequently, the abrasion resistance values increase with increasing starch mass concentration up to as much as $112.2 \%$ for standard starching and $135.6 \%$ for the prewetting starching process, compared to unstarched yarn.

By comparative analysis of the values of the tested abrasion resistance property, it can be concluded that by increasing the starch mass concentration the abrasion resistance of the tested yarns also increases. The most prominent results were obtained by starching with a mass concentration of $10 \%$, which was not the case with the previously tested properties. In addition, it can be concluded that better resilience is achieved by applying a prewetting process, which also has a number of other advantages over the standard conventional process, such as cost reduction (water, electricity and starch) and the overall environmental aspect.

For the abrasion resistance property, a multiple regression analysis was also performed. Based on the estimated values obtained by linear regression analysis together with the values obtained by testing, the correlation values $R^{2}=0.8881$ was achieved for the standard starching process and $\mathrm{R}^{2}=0.9437$ for the prewetting starching process.

\section{Conclusions}

Based on the results obtained by researching the purpose of starching yarns intended for the production of multifunctional woven fabrics for thermal protective clothing, the following conclusions can be summarized:

Yarn breaking force:

- The increase in breaking force is not accompanied by an increase of starch mass concentration.

- The smallest increase in breaking force is evident by applying a starch mass concentration of $7 \%$.

- Starch mass concentrations of $5 \%$ and $10 \%$ do not show significant deviations, meaning that it is unnecessary to starch the yarn with a concentration mass above $5 \%$.

- The prewetting starching process gives better results by increasing the breaking force for all tested samples.

- The indicator of the performed analysis of linear regressions and correlations between the estimated values and the values obtained by testing gives a high correlation coefficient (for $S: R^{2}=0.9339$ and $P: R^{2}=0.9328$ ).

Elongation at break:

- Yarns starched with mass concentration of $5 \%$ show the best results, i.e., the smallest decrease in elasticity.

- Yarns starched by the prewetting process show the smallest elasticity decrease, especially the yarn sample composed of para- and meta-aramid fibers.

- The indicator of the performed analysis of linear regressions and correlations between the estimated values and the values obtained by testing gives a high correlation coefficient (for $S: R^{2}=0.9893$ and $P: R^{2}=0.9822$ ).

Tenacity:

- The tenacity increase is more pronounced for yarns starched with the prewetting process with all mass concentrations.

- By applying a mass concentration of $5 \%$, the best results of yarn tenacity are obtained.

- The indicator of the preformed analysis of linear regressions and correlations between the estimated values and the values obtained by testing gives a high correlation coefficient (for $S: R^{2}=0.9251$ and $P: R^{2}=0.9214$ ).

Abrasion resistance: 
- By increasing the mass concentration, abrasion resistance increases, especially by applying the prewetting starching process.

- The greatest impact of the starching process on abrasion resistance increase is evident for the yarn sample composed of para- and meta-aramid fibers.

- Linear regressions and correlations between testing obtained and analysis of estimated values of wear resistance gives a high correlation coefficient (for S: $R^{2}=0.8881$ and P: $\left.\mathrm{R}^{2}=0.9237\right)$.

It is important to point out that this research gives us an answer to the question: whether yarns used for this specific purpose should be subjected to a starching process and under what conditions. According to the results obtained, it can be finally concluded that the starching process is extremely important in the yarn preparation process. It cannot be neglected and skipped in case of spun yarns of different structures and raw materials. Depending on the yarn composition and its characteristics, individual yarn properties are improved by starching, to a greater or lesser extent. This research proves the justification of high-strength yarn starching, which is reflected in the increase of abrasion resistance, and less in the increase of the breaking force property. The results presented confirm the fact that synthetic and other fibers (which achieve satisfactory yarn strength) still need to be starched, but with lower starch mass concentrations, in order to protect yarn from destruction in the weaving process due to cyclic loads, abrasion on loom elements and static electricity. This research established that the increase of starch mass concentration (and thus starch pickup on yarn) is not accompanied by the improvement of some parameters. In this study, the best results of the tested properties were shown by yarns starched with a lower mass concentration (5\%), which indicates the importance of optimizing the starch mass concentration for each type of yarn, implying lower costs, better quality and efficiency in the weaving process, as well as less environmental pollution.

By applying a prewetting starching process, significantly better results were achieved compared to the standard starching process. Starching of different yarn types using two starching process and different starch masses concentrations, as well as their comparison, certainly represents a strong scientific step forward. The application of such knowledge in the textile industry through the implementation of a new starching process, assuming the initial investment, will result in large savings in various aspects of the fabric production process, in this increasingly widespread field of technical textiles.

Author Contributions: Conceptualization, I.S.; methodology, I.S. and S.K.; formal analysis, I.S., S.K. and I.V.; investigation, I.V.; writing — original draft preparation, I.S., S.K. and I.V.; writing—review and editing, I.S. and S.K.; visualization, I.S.; supervision, S.K. All authors have read and agreed to the published version of the manuscript.

Funding: This work has been fully supported by Croatian Science Foundation under the project IP-2018-01-3170 Multifunctional woven composites for thermal protective clothing.

Institutional Review Board Statement: Not applicable.

Informed Consent Statement: Not applicable.

Data Availability Statement: The data presented in this study is openly available.

Conflicts of Interest: The authors declare no conflict of interest.

\section{References}

1. Sahbaz Karaduman, N.; Karaduman, Y.; Ozdemir, H.; Ozdemir, G. Textile Reinforced Structural Composites for Advanced Applications. In Textiles for Advanced Applications; Kumar, B., Thakur, S., Eds.; IntechOpen: London, UK, 2017.

2. Pan, P.; Sun, G. Functional Textiles for Improved Performance, Protection and Health, 3rd ed.; Woodhead Publishing Limited in Association with The Textile Institute: Cambridge, UK, 2011.

3. Rana, S.; Fangueiro, R. Fibrous and Textile Materials for Composite Applications; Springer: Singapore, 2016.

4. Scott, R.A. Textiles for Protection, 3rd ed.; Elsevier: Cambridge, UK, 2005.

5. Hursa Šajatović, A.; Zavec Pavlinić, D.; Dragčević, Z. Firefighters clothing systems for protection against heat and flame. Tekstil 2013, 62, 160-173.

6. Hu, J. Structure and Mechanics of Woven Fabrics, 3rd ed.; Woodhead Publishing Limited: Cambridge, UK, 2005. 
7. Mandal, S.; Annaheim, S.; Greve, J.; Camenzind, M.; Rossi, R.M. Modeling for predicting the thermal protective and thermophysiological comfort performance of fabrics used in firefighters clothing. Text. Res. J. 2019, 89, 2836-2849. [CrossRef]

8. Mandal, S.; Annaheim, S.; Greve, J.; Camenzind, M.; Rossi, R.M. A categorization tool for fabric systems used in firefighters' clothing based on their thermal protective and thermo-physiological comfort performances. Text. Res. J. 2019, 89, $3244-3259$. [CrossRef]

9. Magdalenić Bujanić, J.; Bujanić, B. Aramid fibres. Polimer 2011, 32, 130-134.

10. Eichhorn, S.; Hearle, J.W.S.; Jaffe, M.; Kikutani, T. Handbook of Textile Fibre Structure; Woodhead Publishing: Cambridge, UK, 2009.

11. Brnada, S.; Schwarz, I.G. Analysis of Electrostatic Conductivity of the Woven Fabrics with Bicomponent Carbon Fibres for Protective Clothing. In Proceedings of the 5th International Professional and Scientific Conference, Zadar, Croatia, 17-22 September 2014.

12. Song, G.; Mandal, S.; Rossi, R.M. Thermal Protective Clothing for Firefighters; Woodhead Publishing in association with The Textile Institute, Woodhead Publishing Series; Woodhead Publishing Limited: Cambridge, UK, 2017.

13. Mandal, S.; Song, G.; Ackerman, M.; Paskaluk, S.; Gholamreza, F. Characterization of textile fabrics under various thermal exposures. Text. Res. J. 2013, 83, 1005. [CrossRef]

14. Goswami, B.C.; Anandjiwala, R.D.; Hall, D.M. Textile Sizing; Marcel Dekker, Inc.: New York, NY, USA, 2004.

15. Gudlin Schwarz, I.; Kovacevic, S.; Dimitrovsk, K. Comparative Analysis of the Standard Sizing Process and the Pre-wet Sizing Process. Fibres Text. East. Eur. 2011, 19, 131-137.

16. Horrocks, A.R.; Subhash, C.A. Handbook of Technical Textile; Woodhead Publishing: Cambridge, UK, 2016.

17. Johnen, A. Experiences in wet-in-wet sizing. Melliand Int. 2005, 11, 34-36.

18. Lewin, M. Cotton Fiber Chemistry and Technology; CRC Press, Taylor \& Francis Group: Boca Raton, FL, USA, 2006.

19. Li, Y.; Hardin, I.R. Enzymatic Scouring of Cotton: Effects on Structure and Properties. Text. Chem. Colorists 1997, 66, 71-76.

20. Ormerod, A.; Sondhelm, W.S. Weaving: Operations and Technology; Woodhead Publishing Limited: Cambridge, UK, 1995.

21. Kovačević, S.; Schwarz, I.; Skenderi, Z. Diversity of spun yarn properties sized with and without prewetting. Ind. Text. 2016, 67, 91-98.

22. Sejri, N.; Harzallah, O.; Viallier, P.; Amar, S.B.; Nasrallah, S.B. Influence of Pre-wetting on the Characteristics of a Sized Yarn. Text. Res. J. 2008, 78, 326-335. [CrossRef]

23. Stegmaier, T.; Wunderlich, W.; Hager, T.; Siddique, A.B.; Sarsour, J.; Planck, H. Chitosan-A sizing agent in fabric productionDevelopment and ecological evaluation. Clean 2008, 36, 279-286. [CrossRef]

24. Kovačević, S.; Dimitrovski, K.; Orešković, V. Optimization of size pick-up on yarn. In Proceedings of the 2nd International Textile, Clothing \& Desing Conference-Magic World of Textiles, Dubrovnik, Croatia, 3-6 October 2004.

25. Kovačević, S.; Schwarz, I.; Brnada, S. Analysis of Size Pick-up and Mechanical and Surface Properties of Multicolored Warps. Text. Res. J. 2008, 78, 158-167. [CrossRef]

26. Nisbet, H. Theory of Sizing; Read Books: Vancouver, BC, Canada, 2010.

27. Sarkodie, B.; Xun, Z.; Zhifeng, Z.; Frimpong, C.; Badoe, W.; Asinyo, B.; Kofi Howard, E. Phosphorylation and Octenylsuccinylation of Acid-Thinned Starch for Enhancing Adhesion on Cotton/Polyester Blend Fibers at Varied Temperature Sizing. Starch Starke 2019, 71, 1-8.

28. Lambiso, S.T.; Murugesan, B.; Rotich, G. Performance Evaluation of Cotton Yarn Sized With Natural Starches Produced From Native Corn, Cassava and Potato Starches. J. Tex. Sci. Eng. 2019, 9, 1-5.

29. Hebeish, A.; Abdel-Rahman, A.; El-Hilw, Z.; Hashem, M. Cationized Starch Derived from Pre-Oxidized Starch for Textile Sizing and Printing. Starch Stärke 2005, 57, 616-623. [CrossRef] 